\title{
ASSESSMENT OF THE RESPONSE OF PREFABRICATED HOUSE TO THE EXPLOSION OF GAS-AIR MIXTURE
}

\author{
Miroslav MYNARZ ${ }^{1}$, Adam SKOPAL ${ }^{2}$
}

Research article

$\begin{array}{ll}\text { Abstract: } & \text { In this contribution, simple computational approaches to the determination of blast load } \\ & \text { and its effects on the structure of prefabricated house are proved. Blast waves parameters } \\ \text { are defined for chosen room during natural gas escape. Blast load parameters are calculated } & \\ \text { by several methods. Estimation of its effects on the structure is modelled using numerical } & \text { modelling. } \\ \text { Keywords: } & \text { Explosion, natural gas, structure response, building structure, prefabricated house. }\end{array}$

\section{Introduction}

Statistical data of Fire Rescue Service of the Czech Republic points to long-term unfavourable state of high number of gas explosions in buildings. It especially concerns natural gas explosions. Despite all the efforts to intercept the controlled risk, an accident may occur. Work experience show more and more the necessity of paying attention to the management of health and safety. Both these aspects are above all involved in lives and health of persons but also in substantial financial costs in cases of serious accident or emergency. To reduce the influence of the accident associated with explosion, blast waves explosion parameters should be taken into consideration while designing the objects, equipment, systems or its surroundings. It is required to optimize the construction on the basis of blast load information. Wide and complex issue of shock wave propagation includes a series of uncertainties and solution procedures. Knowledge of blast waves parameters is necessary for the detailed solution of interaction with the structure. Following these parameters, blast load could be determined.

\section{Materials and methods}

\section{Determination of blast load in a partly closed space}

Standard (ČSN EN 1991-1-7, 2007) could be used for determination of load caused by the explosion for all parts of structural and civil engineering where gas is used or regulated, or where explosives (such as explosive gas or fluids forming explosion vapors) are stored, or where gas is stored or transported (e. g. chemical equipment, containers, tanks, facilities for wastewaters, residential buildings with gas installations, energetic ducts, road and rail tunnels). For standard purposes, the explosion is defined as a rapid chemical reaction of dust, gas and vapor in the air. Throughout we have to take into consideration both the transfer of blast waves parameters (high overpressures and temperatures) from non-load bearing elements of the structure to load bearing elements and afterwards their reactions. The pressure caused by an internal explosion depends mainly on the type and homogeneity of explosive mixture, on its concentration, ignition source, on the turbulence caused by internal objects and on the size and quantity of the explosive mixture participating on the explosion effect. If the building should be relieved sufficiently from the effects of the explosion, it must be equipped with the necessary amount of exhaust (relief, vent) areas. For exhaust components, we can consider light roofs, walls, or even sub-areas in the external structures such as windows and doors. For windows and doors, we have to take into account the risk of personal injury caused by broken glass or frames of the filling shattered during the explosion (ČSN EN 1991-1-7, 2007).

\section{Computational procedures for the determination of venting deflagration pressure}

Venting of deflagration means that the enclosure is opened for a short time or permanently during the initiation of deflagration and after the reaching of predefined pressure. The principle of deflagration venting lies in the opening of a vent area after the development of deflagration and the reaching of certain level of vent element reaction pressure. Therethrough, primarily closed inner space is connected with external environment. This reduced

\footnotetext{
VŠB - Technical University of Ostrava, Faculty of Safety Engineering, Ostrava, Czech Republic, miroslav.mynarz@vsb.cz

2 VŠB - Technical University of Ostrava, Faculty of Safety Engineering, Ostrava, Czech Republic, adam.skopal.st@vsb.cz
} 
pressure is called venting deflagration pressure or also reduced pressure (Damec, 2005). To determine venting (reduced) deflagration pressure, a large number of relations, formulas and procedures can be found. Computational methods according to Cubbage and Simmonds, Rasbash and European standard EN 1991-1-7 was chosen for practical application. Theory and computational relations of the above mentioned procedures were previously published in (Mynarz and Šimoník, 2010).

\section{Practical application of computational procedures on the object}

The study deals with the estimation of deflagration power in the case of natural gas leak in a kitchen supposing the creation of potentially explosive atmosphere. The analysis was performed on a prefabricated house of T 06 B-BTS type with 12 floors and 60 residential units, see Fig. 1. In the room, internal (partially bounded) deflagration of methane-air explosive mixture was simulated.

\section{Scenario of the initiation of deflagration}

In the kitchen of prefabricated house, the burner on a gas stove flames out. It can occur in several ways, e. g. while cooking on the stove, heated fluid flows out of a utensil; or due to the malfunction of burner and air circulation around the stove, thereby blowing out the flame; or while igniting gas burner, gas supply is turned off and then restarted again (the main gas valve). If the stove is not equipped with a flame failure safety device, gas supply is not interrupted when the flame extinguishes, and thus the gas begins to spread through the room. The leakage can also occur due to improper handling, leak or crack (hole) on the feed pipe or hose. Afterwards, explosive concentration is forming during mixing with surrounding air. The initiation of explosive mixture most likely occurs when turning on the electrical equipment. A light switch at the $150 \mathrm{~cm}$ distance from the stove was determined as the most likely source of ignition.

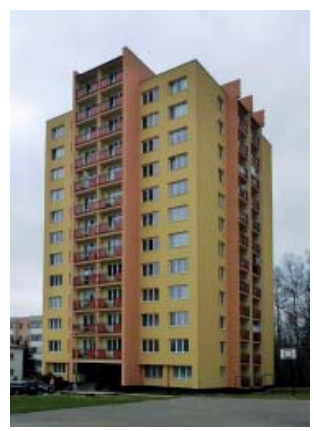

Fig. 1 Prefabricated house T 06 B-BTS (Prefabricated houses, 2010)

\section{Computation of gas leak amount and of the initiation time of explosive concentration}

The kitchen room is of a rectangular shape with floor area 12,3 $\mathrm{m}^{2}$ and clear height of 2,6 m. Gas stove is placed in the corner of the room with common kitchen furniture. Turning off the most powerful burner with nozzle diameter $1,25 \mathrm{~mm}$ and 2,6 kW power (Fík, 2004) was considered for the calculation of the initiation time of explosive concentration, see Tab. 1.

Tab. 1 Parameters for the calculation of explosive concentration in the kitchen of a prefabricated house

\begin{tabular}{|l|l|}
\hline Room dimensions: & \\
- length & $3,56 \mathrm{~m}$ \\
- width & $3,38 \mathrm{~m}$ \\
- height & $2,60 \mathrm{~m}$ \\
\hline Room volume $-\mathrm{V}_{\text {mistnosti }}$ & $31,29 \mathrm{~m}^{3}$ \\
\hline Gas rate - $\mathrm{v}_{\mathrm{CH} 4}$ & $0,273 \mathrm{~m}^{3} \cdot$ hod $^{-1}$ \\
\hline Minimal explosive concentration $-\mathrm{C}_{\mathrm{CH} 4}$ & $4,4 \%$ \\
\hline
\end{tabular}

The estimation of minimal leaked methane amount for the formation of an explosive concentration $V_{C H 4}$ :

$$
V_{C H 4}=\frac{V_{\text {mistnosti }} \cdot C_{C H 4}}{100}=1,38 \mathrm{~m}^{3}
$$

The estimation of minimum time of leakage for the formation of an explosive concentration $t_{\min }$ :

$$
t_{\text {min }}=\frac{V_{C H 4}}{v_{C H 4}}=5,05 \text { hrs } \approx 5 \text { hours } 3 \text { minutes }
$$

The calculation (2) shows that minimum time for the formation of explosive concentration in the room is 5 hours and 3 minutes. However, this time cannot be taken as an exact value because the formation of an explosive concentration is influenced by other factors. To achieve maximum pressure during venting deflagration, explosive mixture does not need to be found throughout the whole area; it just has to occur at the point of ignition source, see Tab. 2. In the case of leakage failure of outside wall, this calculation is irrelevant and it depends only on the size of these leaks; thus the initiation time of explosive concentration may be extended or the explosive concentration does not need to occur at all. 
Tab. 2 Source data about the room and about a range of natural gas leak

\begin{tabular}{|c|c|c|c|c|c|c|c|}
\hline \multicolumn{4}{|c|}{ Disposition of the room } & \multicolumn{3}{c|}{ A range of a leak } \\
\hline Floor & $\begin{array}{c}\text { Function of } \\
\text { the room }\end{array}$ & Area $\left[\mathbf{m}^{2}\right]$ & $\begin{array}{c}\text { Volume of the } \\
\text { room }\left[\mathbf{m}^{\mathbf{3}}\right]\end{array}$ & $\begin{array}{c}\text { Vent area } \\
{\left[\mathbf{m}^{2}\right]}\end{array}$ & Volume $\left[\mathbf{m}^{3}\right]$ & Weight $[\mathbf{k g}]$ & LEL [obj. \%] \\
\hline $2^{\text {nd }}$ floor & kitchen & 12,3 & 31,3 & 2,1 & 1,4 & 0,9 & 4,4 \\
\hline
\end{tabular}

LEL - Lower Explosive Limit

For the determination of deflagration pressures during venting deflagration, three methods were used, see (Mynarz and Šimoník, 2010). Tab. 3 presents the values of deflagration pressures obtained by manual calculation.

Tab. 3 The values obtained from different calculations - comparison

\begin{tabular}{|c|c|c|c|c|}
\hline \multicolumn{2}{|c|}{$\begin{array}{c}\text { Calculation } \\
\text { according to: }\end{array}$} & $\begin{array}{c}\text { Venting } \\
\text { deflagration } \\
\text { pressures } \\
{[\text { [kPa] }}\end{array}$ & $\begin{array}{c}\text { Positive } \\
\text { phase } \tau+ \\
\text { [ms] }\end{array}$ \\
\hline \multirow{2}{*}{1} & $\begin{array}{c}\text { Cubbaga a } \\
\text { Simmondse }\end{array}$ & $\mathrm{P}_{1}$ & 7,43 & \multirow{2}{*}{} \\
\cline { 3 - 4 } 2 & Rasbash & $\mathrm{P}_{2}$ & 16,14 & \multirow{2}{*}{300} \\
\hline 3 & \multirow{2}{*}{ EN - 1991-1-7 } & $\mathrm{p}_{\mathrm{d}}$ & 5 & \multirow{2}{*}{300} \\
\cline { 3 - 4 } & $\mathrm{p}_{\mathrm{d}}$ & 14,11 & \multirow{2}{*}{} \\
\hline
\end{tabular}

\section{Description of the structure and load}

Assessed building has twelve floors. The structural system consists of non-prestressed reinforced-concrete prefabricated panels connected by welding of reinforcement and then pouring the cement mixture. The building forms a transverse load-bearing system with preceded cladding. At the tower house in the longitudinal way, a wing (tract) runs in a module of $3,6 \mathrm{~m}$ with a staircase at the facade and with elevators. Transversal walls with module of $7 \times 3,6 \mathrm{~m}$ run perpendicularly to the hall, symmetrically on both sides. Building depth is $12 \mathrm{~m}$ and the construction depth of a floor is $2,8 \mathrm{~m}$. The disposition of one room is presented in Fig. 2.

In the case study, gas leak was considered on the second floor. Firstly, blast load was assumed as a uniformly distributed static pressure applied effectively at the same time to all the areas enclosing the space. Dynamic load was considered in the next stage. Opening of vent areas was supposed, i. e. venting deflagration is the matter. Positive phase duration of blast wave is a very important parameter for the estimation of blast effect. This time period ranges in the order of hundreds of milliseconds in the case of gas mixture explosion. In this study, the positive phase of blast wave was estimated as $300 \mathrm{~ms}$, mainly based on our own measurements and experience.

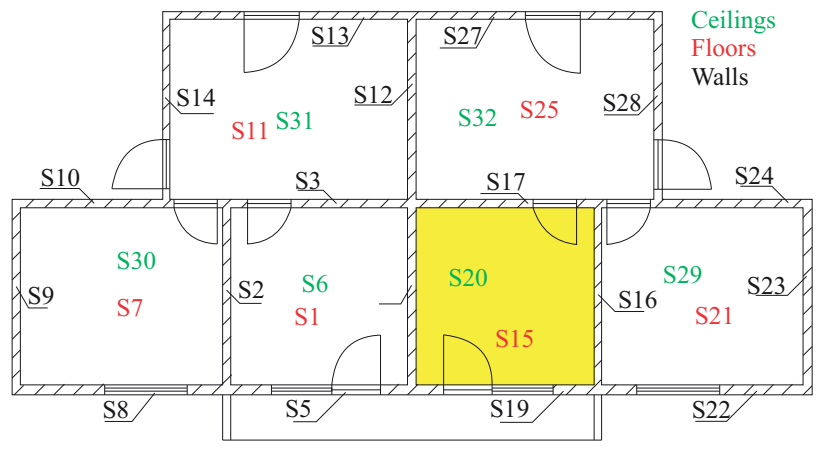

Fig. 2 Layout of involved parts of residential units with denoted structural elements (yellow section represents the room where the deflagration was simulated in)

\section{Computation of wall failure of the room}

After the estimation of deflagration pressures and according to the demands on results accuracy, the structure could be assessed, either by simplified way or by sophisticated calculation using numerical models. Software application based on the finite element method was used for the calculations. Blast wave is acting with uniformly continuous distribution perpendicular to the middle plain of the wall with duration of $0,3 \mathrm{~s}$ and overpressure value of $23,78 \mathrm{kPa}$. Reinforced concrete is considered a constructional material. The exact parameters of the material are given in Tab. 4. The dimensions of single surface elements are listed below in Tab. 5 .

Tab. 4 Material characteristic of reinforced concrete of the prefabricated house

\begin{tabular}{|l|c|}
\hline Concrete & C30/37 \\
\hline Reinforcement & B 400A \\
\hline Unit weight & $2500 \mathrm{~kg} \cdot \mathrm{m}^{-3}$ \\
\hline Modulus of elasticity E & $32800 \mathrm{MPa}$ \\
\hline Poisson's ratio & 0,2 \\
\hline Logarithmic decrement & 0,2 \\
\hline
\end{tabular}


Tab. 5 Dimensions of structural elements

\begin{tabular}{|l|l|l|}
\hline $\begin{array}{c}\text { Type of structural } \\
\text { element }\end{array}$ & $\begin{array}{c}\text { Element (see } \\
\text { fig. 2) }\end{array}$ & $\begin{array}{c}\text { Dimensions }(\mathbf{l} \text { h } \\
\mathbf{x ~ w ) ~ i n ~ m m ~}\end{array}$ \\
\hline Wall panel & $\mathrm{S} \mathrm{2,4,9,16,23}$ & $3560 \times 2600 \times 140$ \\
\hline External panel & $\mathrm{S} 8,22$ & $3710 \times 2600 \times 200$ \\
\hline External panel & $\mathrm{S} 5,19$ & $3380 \times 2600 \times 200$ \\
\hline Wall panel & $\mathrm{S} 10,24$ & $3710 \times 2600 \times 140$ \\
\hline Wall panel & $\mathrm{S} 3,17$ & $3380 \times 2600 \times 140$ \\
\hline Wall panel & $\mathrm{S} 12,14,28$ & $3450 \times 2600 \times 140$ \\
\hline Wall panel & $\mathrm{S} 13,27$ & $4560 \times 2600 \times 140$ \\
\hline Ceiling panel & $\mathrm{S} 11,25,31,32$ & $4560 \times 3450 \times 150$ \\
\hline Ceiling panel & $\mathrm{S} 1,6,15,20$ & $3560 \times 3380 \times 150$ \\
\hline Ceiling panel & $\mathrm{S} 7,21,29,30$ & $3710 \times 3560 \times 150$ \\
\hline
\end{tabular}

Structure response was investigated by static and dynamic computations. For the calculations, several simplifications were accepted (Makovička and Makovička, 2008). These are:

- blast wave with planar face (acting without phase shift),

- for static load, blast wave effect is consider a continuous, surface and uniform distribution of the whole element (perpendicular to its plane) or the whole structure,

- for dynamic load, blast wave effect is focused into the geometrical centres of single areas of the structure,

- a course of pressure rise (impulse) has a triangular shape and its peak value corresponds to the maximum overpressure during internal explosion after the opening of vent areas.

\section{Results}

\section{Modal analysis}

The executing of modal analysis provides the natural frequencies of the structure. For greater accuracy of results, mesh is refined to $0,2 \mathrm{~m}$ for the length of the side of surface element. A total of 10 natural frequencies were calculated on discretisation final-element model, see Tab. 6. The same number of free vibration mode shapes was solved; the first of them (Fig. 3) is usually the most important shape for the structure under blast load.

Tab. 6 Natural frequencies

\begin{tabular}{|c|c|c|c|c|c|}
\hline $\mathbf{N}$ & $\mathbf{1}$ & $\mathbf{2}$ & $\mathbf{3}$ & $\mathbf{4}$ & $\mathbf{5}$ \\
\hline $\mathrm{f}[\mathrm{Hz}]$ & 10,87 & 18,13 & 22,58 & 25,51 & 42,57 \\
\hline $\mathrm{T}[\mathrm{sec}]$ & 0,092 & 0,055 & 0,044 & 0,039 & 0,023 \\
\hline $\mathbf{N}$ & $\mathbf{6}$ & $\mathbf{7}$ & $\mathbf{8}$ & $\mathbf{9}$ & $\mathbf{1 0}$ \\
\hline $\mathrm{f}[\mathrm{Hz}]$ & 43,75 & 44,59 & 45,81 & 46,25 & 47,26 \\
\hline $\mathrm{T}[\mathrm{sec}]$ & 0,022 & 0,022 & 0,021 & 0,021 & 0,021 \\
\hline
\end{tabular}

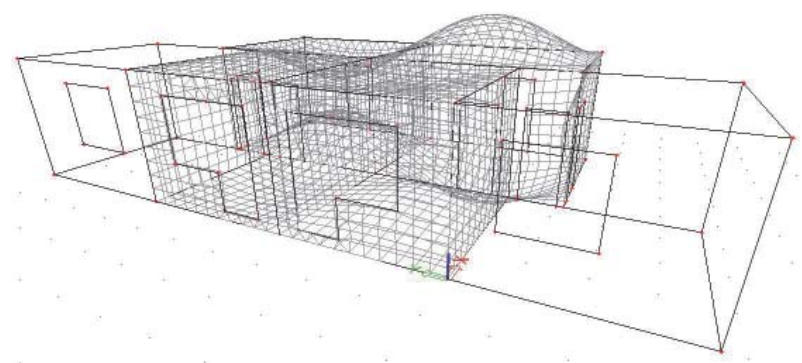

Fig. 3 The first free vibration mode shape

\section{Equivalent static load}

Equivalent static load is obtained by multiplying the calculated deflagration pressure by the dynamic coefficient $\delta$. The dynamic coefficient value is computed according to the formula (3) after substituting the values from Tab. 7.

Tab. 7 The values for dynamic coefficient calculation

\begin{tabular}{|l|c|}
\hline $\mathrm{k}_{\mathrm{m}}$ - coefficient of ductility [-] & 1,50 \\
\hline $\mathrm{T}_{(\mathrm{i})}$ - $\mathrm{i}$-th natural frequency; in this case it is $\mathrm{T}_{1}[\mathrm{~s}]$ & 0,0920 \\
\hline$\tau+$ - positive phase $[\mathrm{s}]$ & 0,30 \\
\hline
\end{tabular}

$$
\frac{1}{\delta}=\frac{T_{(i)} \cdot \sqrt{2 \cdot k_{m}-1}}{\pi \cdot \tau^{+}}+\frac{1-\frac{1}{2 \cdot k_{m}}}{1+0,7 \cdot \frac{T_{(i)}}{\tau^{+}}} \Rightarrow \delta=1,46^{(3)}
$$

The next step is to calculate the equivalent static load $P_{e k v}$ which is obtained from the following equation:

$$
P_{e k v}=\delta \cdot P_{m}=34,62 \mathrm{kPa}
$$

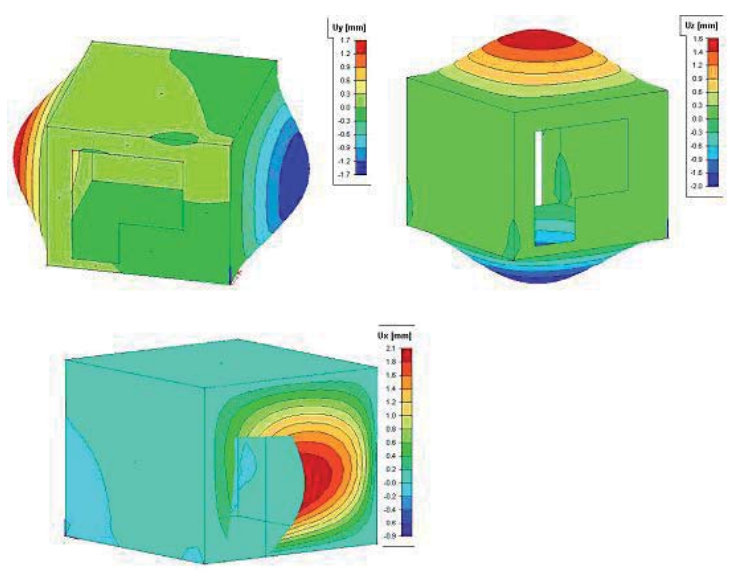

Fig. 4 Graphic visualization of slabs deflection at the equivalent static modelling of the explosion

\section{Manual calculation of the response of the wall}

For calculation, areas with the absence of windows (S4, S15, S16 and S20) were selected. The computational procedure is carried out according 
to (Bareš, 1989). Tab. 8 shows the values used for calculation according to the formula (5); pin bearing around the perimeter of panels is assumed.

Tab. 8 The values for manual calculation of slabs deflection

\begin{tabular}{|l|c|c|c|}
\hline & $\begin{array}{c}\text { Wall S4, } \\
\text { S16 }\end{array}$ & $\begin{array}{c}\text { Ceiling } \\
\text { S15 }\end{array}$ & $\begin{array}{c}\text { Ceiling } \\
\text { S20 }\end{array}$ \\
\hline Modulus of elasticity E [MPa] & 32800 & 32800 & 32800 \\
\hline Sides ratio lx/ly [-] & 1,37 & 1,05 & 1,05 \\
\hline Length of the side 1x [m] & 3,56 & 3,56 & 3,56 \\
\hline Deflagration pressure p [MPa] & 0,034 & 0,034 & 0,034 \\
\hline $\begin{array}{l}\text { Thickness of the structure } \\
\text { h [m] }\end{array}$ & 0,14 & 0,15 & 0,15 \\
\hline$\beta[-]$ & 0,024 & 0,044 & 0,044 \\
\hline
\end{tabular}

$$
w_{s}=\beta \cdot \frac{q \cdot l_{x}^{4}}{E \cdot h^{3}}
$$

\section{Discussion}

The comparison of single values is given in Tab. 9. Therefrom, it is evident that dynamical loads implicate the largest deformations (deflections) in the structure. Equivalent static computation using software corresponds to the manual calculation. Deflections arising from the dynamic load are nearly double compared to the static load deflections but their values are still low, so the structure failure is not likely.

After the evaluation of final maximum structure deflections, it can be stated that in the case of shock wave occurrence, the blast effects (presented for example in (Damec, 2005), Table 6-1) impact the structure differently at the same pressure value. According to the (Makovička and Janovský, 2008), the shock wave of overpressure value of $24 \mathrm{kPa}$ implicates considerable disturbance of urban building - that was not confirmed for the case of modelled structure.
Tab. 9 Deflections comparison by blast effect on the structure

\begin{tabular}{|c|c|c|c|c|c|c|}
\hline \multirow{2}{*}{$\begin{array}{c}\text { Calculated } \\
\text { values } \\
\text { [mm] }\end{array}$} & \multicolumn{2}{|c|}{$\begin{array}{c}\text { Maximum } \\
\text { deflection } \\
\text { in the } X \\
\text { direction }\end{array}$} & \multicolumn{2}{|c|}{$\begin{array}{c}\text { Maximum } \\
\text { deflection in } \\
\text { the } Y \text { direction }\end{array}$} & \multicolumn{2}{|c|}{$\begin{array}{c}\text { Maximum } \\
\text { deflection in the } \\
\mathrm{Z} \text { direction }\end{array}$} \\
\hline & $\begin{array}{l}\text { wall } \\
\text { S17 }\end{array}$ & $\begin{array}{l}\text { wall } \\
\text { S19 }\end{array}$ & $\begin{array}{c}\text { wall } \\
\text { S4 }\end{array}$ & $\begin{array}{l}\text { wall } \\
\text { S16 }\end{array}$ & $\begin{array}{c}\text { ceiling } \\
\text { S15 }\end{array}$ & $\begin{array}{c}\text { ceiling } \\
\text { S20 }\end{array}$ \\
\hline Static & 2,1 & 0,9 & 1,7 & 1,7 & 2 & 1,6 \\
\hline Dynamic & 2,1 & 0,7 & 3,2 & 3,2 & 3,8 & 3,5 \\
\hline Manual & & & 1,5 & 1,5 & 2,5 & 2 \\
\hline
\end{tabular}

The authors drew the conclusion that, in the terms of prefabricated house, internal venting gas deflagration does not cause sufficiently strong overpressure to cause the failure of assessed structure.

\section{Conclusion}

According to (Damec, 2005) or (Makovička and Janovský, 2008), if the deflagration overpressure is known, it is possible to estimate probable damages to the structure. In the case when more detailed assessment of selected part of the structure is required, numerical modelling can be used. On the basis of venting deflagration computations in a dwelling space of prefabricated building, deflagration pressures were obtained according to different methods in the range from $14,11 \mathrm{kPa}$ to 23,78 kPa (see Tab. 3). For calculated overpressure, partially confined explosion in assessed object should cause breaking the glass window panels or bursting the door wing. However, numerical computation did not make out the failure of wall or ceiling panels as a result of explosion. Calculated stresses and internal forces do not exceed the strength of the reinforcedconcrete elements and neither is probable the considerable cracks development on the structure.

\section{References}

ČSN EN 1991-1-7:2007. Action on structures - General actions - Accidental actions. (in Czech)

DAMEC, Jaroslav (2005). Explosion prevention. $1^{\text {st }}$ edition. Ostrava: edition SPBI, 2005. 188 p. ISBN 80-8611121-0. (in Czech)

MYNARZ, Miroslav, ŠIMONÍK, Zdeněk (2010). Assessment Methods for Explosion Load Parameters of Chosen Building Structure. Spektrum, Ostrava, 2010, vol. 10, no. 2, p. 24-26, ISSN 1211-6920. (in Czech)

EKOWATT. Prefabricated houses [online]. Ekowatt, 2010 [cit. 2011-06-20]. Available at: http://panelovedomy. ekowatt.cz/katalogy/2-panelove-soustavy/76-t-06-b (in Czech)

FÍK, Josef (2004). Gas appliances (I) [online]. Topinfo s.r.o., 2004 [cit. 2011-06-20]. Available at: http://www. tzb-info.cz/2019-plynove-spotrebice-i (in Czech)

MAKOVIČKA, Daniel, MAKOVIČKA, Daniel jr. (2008). Response of the structures at blast load and their protection - Approximate determination of response of the structure under blast load (in Czech). $1^{\text {st }}$ edition. Ostrava: edition SPBI, 2008. 23 p. ISBN 978-80-01-03991-5.

BARE ̌̌, Richard (1989). Tables for calculation of slabs and walls. $3^{\text {rd }}$ edition. Praha: SNTL - Nakladatelství technické literatury, 1989. 624 p. ISBN 04-708-89. (in Czech)

MAKOVIČKA, Daniel, JANOVSKÝ, Břetislav et al. (2008). Handbook of explosion protection of the buildings. $1^{\text {st }}$ edition. Praha: Česká technika - nakladatelství ČVUT, 2008. 185 p. ISBN 978-80-01-04090-4. (in Czech) 